\title{
The Effects of Mn-doping and Electrode Material on the Resistive Switching Characteristics of $\mathrm{ZnO}_{\mathrm{x}} \mathrm{S}_{1-\mathrm{x}}$ Thin Films on Plastic
}

\author{
Yong Han \\ Department of Nano Semiconductor Engineering, Korea University, Seoul 137-701 and Hynix Semiconductor Inc., Ichon \\ 467-701, Korea \\ Kyoungah $\mathrm{Cho}^{\dagger}$ and Sukhyung Park \\ Department of Electrical Engineering, Korea University, Seoul 137-701, Korea
}

\author{
Sangsig $\mathrm{Kim}^{+}$ \\ Department of Nano Semiconductor Engineering and Department of Electrical Engineering, Korea University, Seoul 137- \\ 701, Korea
}

Received February 4, 2013; Revised December 3, 2013; Accepted December 14, 2013

\begin{abstract}
In this study, the effects of Mn-doping and the electrode materials on the memory characteristics of $\mathrm{ZnO}_{\mathrm{x}} \mathrm{S}_{1-\mathrm{x}}$ resistive random access memory (ReRAM) devices on plastic are investigated. Compared with the undoped $\mathrm{Al} / \mathrm{ZnO}_{x} \mathrm{~S}_{1-x} / \mathrm{Au}$ and $\mathrm{Al} / \mathrm{ZnO}_{\mathrm{x}} \mathrm{S}_{1-\mathrm{x}} / \mathrm{Cu}$ devices, the Mn-doped ones show a relatively higher ratio of the high resistance state (HRS) to low resistance state (LRS), and narrower resistance distributions in both states. For the $\mathrm{ZnO}_{\mathrm{x}} \mathrm{S}_{1-\mathrm{x}}$ devices with bottom electrodes of $\mathrm{Cu}$, more stable conducting filament paths are formed near these electrodes, due to the relatively higher affinity of copper to sulfur, compared with the devices with bottom electrodes of Au, so that the distributions of the set and reset voltages get narrower. For the $\mathrm{Al} / \mathrm{ZnO}_{\mathrm{x}} \mathrm{S}_{1-\mathrm{x}} / \mathrm{Cu}$ device, the ratio of the HRS to LRS is above $10^{6}$, and the memory characteristics are maintained for $10^{4} \mathrm{sec}$, which values are comparable to those of ReRAM devices on Si or glass substrates
\end{abstract}

Keywords: $\mathrm{ZnO}_{\mathrm{x}} \mathrm{S}_{1-x}$, Resistive switching, Doping effect, Unipolar

\section{INTRODUCTION}

Recently, resistive random access memory (ReRAM) devices on plastic have been intensively studied in the field of plastic based non-volatile memories, since they can easily be fabricated below the glass transition temperatures of plastic [1-4]. Compared to those on Si or glass, the performances of ReRAM devices on plas-

${ }^{\dagger}$ Author to whom all correspondence should be addressed:

E-mail: chochem@korea.ac.kr, sangsig@korea.ac.kr

Copyright @2014 KIEEME. All rights reserved.

This is an open-access article distributed under the terms of the Creative Commons Attribution Non-Commercial
License (httr:///creativecommons.org/licenses/by-nc/3.0) which permits unrestricted noncommercial use.

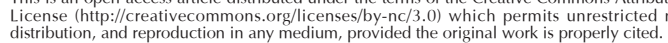

tic have not been very satisfactory [5-8]. Hence, there have been many attempts to improve their performance $[2,9,10]$. More recently, the ternary compound, $\mathrm{ZnO}_{\mathrm{x}} \mathrm{S}_{1-\mathrm{x}}$, has emerged as one of the materials that could be used to improve the characteristics of plastic-based ReRAM devices $[11,12]$. Plastic-based ReRAM devices made of $\mathrm{ZnO}_{\mathrm{x}} \mathrm{S}_{1-\mathrm{x}}$ exhibit retention properties comparable to those of ReRAM devices on Si or glass. On the other hand, doping in resistive switching materials and electrode materials are known to have significant effects on the memory characteristics of ReRAM devices [13-17]. The resistive characteristics of the materials are influenced by several factors, such as the combination of top/bottom electrode materials, and resistive material/ electrode materials. In addition, several factors affect the mode 
of resistive switching, which are classified into two types: unipolar or bipolar modes. In this study, therefore, we investigate the effects of doping and electrode materials on the performances of ReRAM devices made of $\mathrm{ZnO}_{\mathrm{x}} \mathrm{S}_{1-\mathrm{x}}$. Mn, as the dopant used in this study, is one of the most promising materials to facilitate the resistive switching of zinc manganese oxides [13,14,18].

\section{EXPERIMENTS}

$\mathrm{Au}$ and $\mathrm{Cu}$ bottom electrodes were deposited on a polyethersulfone (PES) plastic substrate by thermal evaporation, and the dc sputtering method, respectively. A resistive switching thin film with a thickness of $35 \mathrm{~nm}$ was then deposited on the electrode layers in an RF magnetron sputtering system with a watercooling unit. $\mathrm{ZnO}_{\mathrm{x}} \mathrm{S}_{1-\mathrm{x}}$ and $\mathrm{ZnO}_{\mathrm{X}} \mathrm{S}_{1-\mathrm{x}}: \mathrm{Mn}$ as the resistive switching materials used in this study were sputtered from $\mathrm{ZnO}_{\mathrm{x}} \mathrm{S}_{1-\mathrm{x}}$ and $1 \% \mathrm{Mn}$-doped $\mathrm{ZnO}_{\mathrm{x}} \mathrm{S}_{1-\mathrm{x}}$ targets for $20 \mathrm{~min}$, under a mixture of $\mathrm{Ar}$ and $\mathrm{O}_{2}$, at a pressure of $6.0 \mathrm{mTorr}$, with a sputtering power of $120 \mathrm{~W}$, respectively. As the top electrodes, dot patterned $\mathrm{Al}$ electrodes with a diameter of $200 \mu \mathrm{m}$ were deposited on the resistive switching thin film, by thermal evaporation. The electrical characteristics of the memory devices were examined with an HP4155C semiconductor parameter analyzer, at room temperature, in air.

\section{RESULTS AND DISCUSSION}

Figure 1 exhibits typical I-V curves of the Mn-doped and undoped $\mathrm{Al} / \mathrm{ZnO}_{\mathrm{x}} \mathrm{S}_{1-\mathrm{x}} / \mathrm{Au}$ and $\mathrm{Al} / \mathrm{ZnO}_{\mathrm{x}} \mathrm{S}_{1-\mathrm{x}} / \mathrm{Cu}$ devices in the positive voltage regions, with log scales, indicating unipolar resistive switching. Once a dc voltage is applied, tiny conducting filaments are formed, due to the alignment of the defects. In the low resistance state (LRS), the I-V relation exhibits Ohmic behavior, until these tiny filaments are ruptured by the Joule heating effect, which occurs in the high resistance state (HRS) [19-22]. The memory characteristics are achieved by switching between the LRS and HRS. Regardless of the Mn-doping, LRS of the $\mathrm{ZnO}_{\mathrm{x}} \mathrm{S}_{1}$. ${ }_{x}$ based ReRAM devices exhibits the Ohmic conduction behavior with a slope of $\sim 1$, which is concerned with the formation of conductive filaments in the devices, during the set process. The conduction mechanism in HRS is more complicated, which is in good agreement with a typical trap-controlled space charge limited conduction (SCLC), consisting of Ohmic regions $(\mathrm{I} \propto \mathrm{V})$, the Child's law region $\left(I \propto V^{2}\right)$, and the trap-filled limit conduction region $[2,19,20]$.

Compared with the undoped $\mathrm{ZnO}_{x} \mathrm{~S}_{1-\mathrm{x}}$ based ReRAM devices, the magnitude of the current flowing in HRS of the Mn-doped devices gets lower; and consequently, the ratios of LRS/HRS become larger. Han et al. reported that Mn-doped samples become more resistive, because the doping of $\mathrm{Mn}$ ions depresses the concentration of intrinsic donors, such as interstitial zincs and oxygen vacancies in $\mathrm{ZnO}$ ceramics [23]. The Mn doping effect shown in this study is similar to the widening in the memory window of other metal doped-ReRAM devices, due to the increase in the resistivity of the HRS $[13,17,18]$. In this study, when the Mn ions are doped into the resistive switching material of $\mathrm{ZnO}_{\mathrm{x}} \mathrm{S}_{1-\mathrm{x}}$, the ratio increases from $2.2 \times 10^{5}$ to $2.4 \times 10^{6}$ for the $\mathrm{Cu}$-bottom device, and from $5.9 \times 10^{4}$ to $3.3 \times 10^{5}$ for the Au-bottom devices.

The distributions of the set and reset voltages reflect the effects of the Mn-doping and the electrode materials on the ReRAM characteristics, as shown in Fig. 2. In comparing the (a) Mndoped and undoped $\mathrm{Al} / \mathrm{ZnO}_{\mathrm{x}} \mathrm{S}_{1-\mathrm{x}} / \mathrm{Au}$ devices, and (b) $\mathrm{Al} / \mathrm{ZnO}_{\mathrm{x}} \mathrm{S}_{1-\mathrm{x}} /$ $\mathrm{Cu}$ devices, the Mn-doped devices exhibit narrower distributions of the set and reset voltages, than the undoped devices.
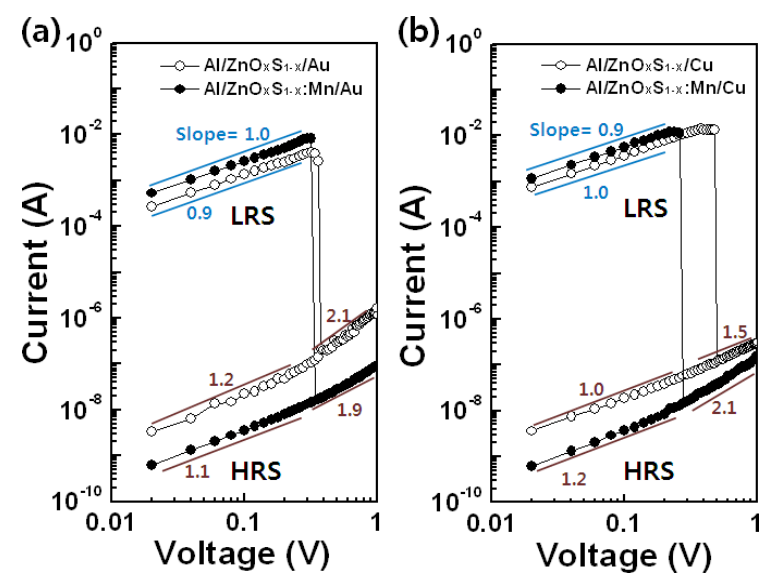

Fig. 1. Log I and Log V plots of the LRS and HRS. (a) The Mn-doped and undoped $\mathrm{Al} / \mathrm{ZnO}_{\mathrm{x}} \mathrm{S}_{1-\mathrm{x}} / \mathrm{Au}$ devices and (b) the Mn-doped and undoped $\mathrm{Al} / \mathrm{ZnO}_{\mathrm{x}} \mathrm{S}_{1-\mathrm{x}} / \mathrm{Cu}$ devices.

(a)

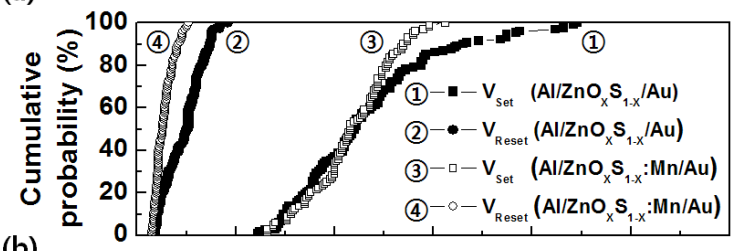

(b)

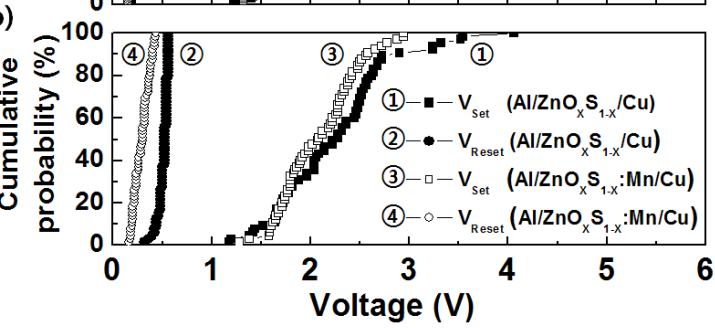

Fig. 2. Set and reset voltage distributions from the continuous measurements over 100 cycles. (a) The Mn-doped and undoped Al/ $\mathrm{ZnO}_{\mathrm{x}} \mathrm{S}_{1-\mathrm{x}} / \mathrm{Au}$ devices and (b) the Mn-doped and undoped $\mathrm{Al} / \mathrm{ZnO}_{\mathrm{x}} \mathrm{S}_{1-\mathrm{x}} /$ $\mathrm{Cu}$ devices.

In the metal-doped resistive switching layer, the formation and rupture of the conducting filaments occur in a localized manner, due to the Mn ions around the conducting filaments; and consequently, the Mn-doped devices have relatively narrower distributions of the set and reset voltages [16,17]. Moreover, the $\mathrm{Al} / \mathrm{ZnO}_{\mathrm{x}} \mathrm{S}_{1-\mathrm{x}} / \mathrm{Cu}$ devices show narrower distributions than the $\mathrm{Al} / \mathrm{ZnO}_{\mathrm{x}} \mathrm{S}_{1-\mathrm{x}} / \mathrm{Au}$ ones. This is attributed to the higher affinity of copper to sulfur than that of gold, which forms more stable conducting filament paths near the electrodes of $\mathrm{Cu}$ [24].

Because the distribution of the set/reset voltages is concerned with a rearrangement of filaments with a tree-like structure, stable conducting filament paths formed on the electrode are responsible for the narrower distribution of the set/reset voltages. Furthermore, careful comparison of the endurance characteristics of our undoped devices reveals that $\mathrm{Cu}$ is more appropriate as a bottom electrode material than $\mathrm{Au}$ for the $\mathrm{ZnO}_{\mathrm{x}} \mathrm{S}_{1-\mathrm{x}}$ ReRAM devices, as shown in Fig. 3. The resistance of HRS in the Al/ $\mathrm{ZnO}_{\mathrm{x}} \mathrm{S}_{1-\mathrm{x}} / \mathrm{Cu}$ device fluctuates less significantly than in the $\mathrm{Al} /$ $\mathrm{ZnO}_{\mathrm{x}} \mathrm{S}_{1-\mathrm{x}} / \mathrm{Au}$ device, which is closely related to the narrower distribution of the set/reset voltages observed in the $\mathrm{Al} / \mathrm{ZnO}_{\mathrm{x}} \mathrm{S}_{1-\mathrm{x}} / \mathrm{Cu}$ device.

The resistance variations for each of the undoped [(a),(c)] and 

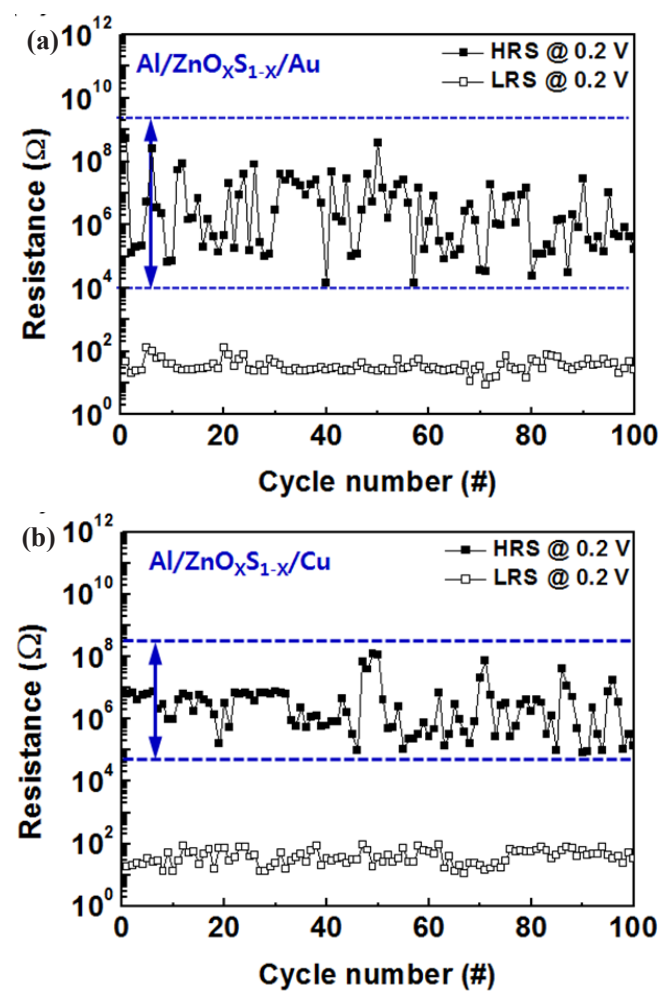

Fig. 3. Endurance characteristics of (a) the undoped $\mathrm{Al} / \mathrm{ZnO}_{\mathrm{x}} \mathrm{S}_{1-\mathrm{x}} / \mathrm{Au}$ and (b) the $\mathrm{Al} / \mathrm{ZnO}_{\mathrm{x}} \mathrm{S}_{1-\mathrm{x}} / \mathrm{Cu}$ devices, at room temperature. (a)

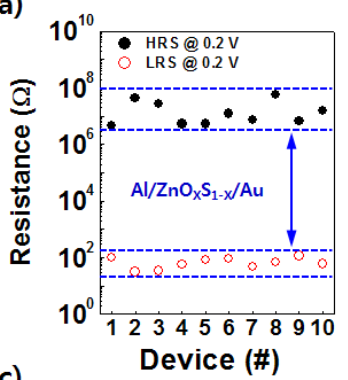

(c)

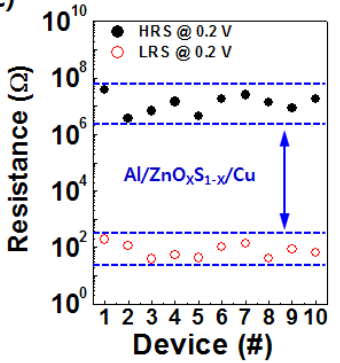

(b)

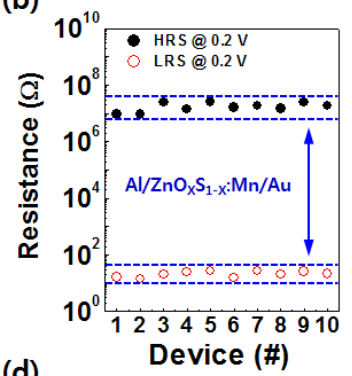

(d)

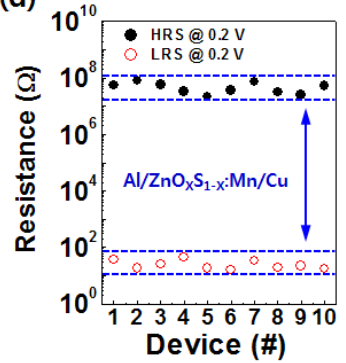

Fig. 4 . The mean resistance values measured at $0.2 \mathrm{~V}$ in the HRS and LRS, obtained from experiments performed 30 times per sample. (a) The undoped $\mathrm{Al} / \mathrm{ZnO}_{\mathrm{x}} \mathrm{S}_{1-\mathrm{x}} / \mathrm{Au}$ devices, (b) the Mn-doped $\mathrm{Al} / \mathrm{ZnO}_{\mathrm{x}} \mathrm{S}_{1-\mathrm{x}} /$ $\mathrm{Au}$ devices, (c) the undoped $\mathrm{Al} / \mathrm{ZnO}_{\mathrm{x}} \mathrm{S}_{1-\mathrm{x}} / \mathrm{Cu}$ devices, and (d) the $\mathrm{Mn}$ doped $\mathrm{Al} / \mathrm{ZnO}_{\mathrm{x}} \mathrm{S}_{1-\mathrm{x}} / \mathrm{Cu}$ devices.

Mn-doped [(b),(d)] devices are represented in Fig. 4. The data points are the average values of the resistances (of ten devices with the same doping and electrode materials), obtained from measurements repeated 30 times. The dotted lines indicate the minimum and maximum values of the resistances, for each of the four different devices. For the Mn-doped devices, the ratios (a)
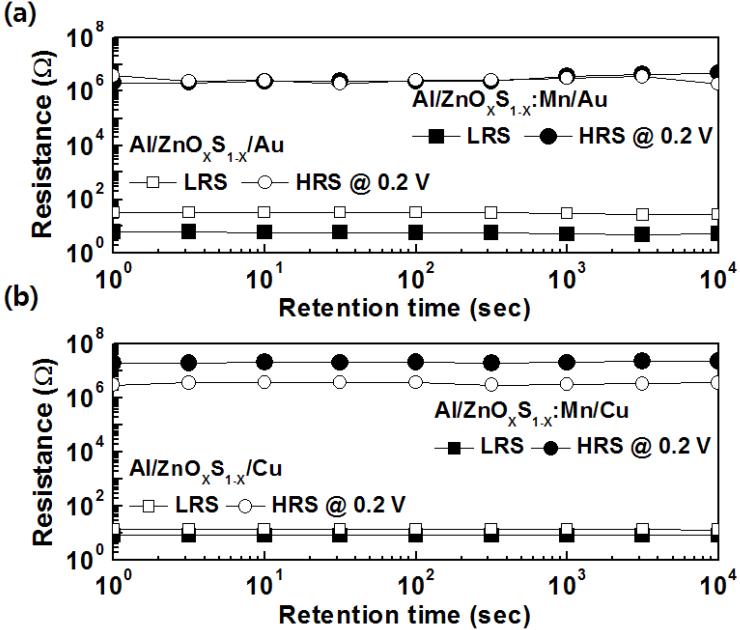

Fig. 5. Retention characteristics of (a) Mn-doped and undoped Al/ $\mathrm{ZnO}_{\mathrm{x}} \mathrm{S}_{1-\mathrm{x}} / \mathrm{Au}$ and (b) $\mathrm{Al} / \mathrm{ZnO}_{\mathrm{x}} \mathrm{S}_{1-\mathrm{x}} / \mathrm{Cu}$ devices, at room temperature.

of the HRS to LRS are increased, but the variations in the resistances of the HRS and LRS are decreased (compared with the undoped devices), which are virtually the same as the results shown in Fig. 2. Consequently, the Mn-doping in the resistive materials causes an increase in the ratio of the HRS to LRS, and a decrease in the resistance fluctuations $[13,17,25]$.

Figure 5 shows the retention properties of (a) the Mn-doped and undoped $\mathrm{Al} / \mathrm{ZnO}_{\mathrm{x}} \mathrm{S}_{1-\mathrm{x}} / \mathrm{Au}$ devices, and (b) $\mathrm{Al} / \mathrm{ZnO}_{\mathrm{x}} \mathrm{S}_{1-\mathrm{x}} / \mathrm{Cu}$ devices, measured at room temperature. Irrespective of the electrode materials, and with or without Mn-doping, the memory characteristics are maintained for $10^{4} \mathrm{sec}$. The reliabilities of $\mathrm{ZnO}_{\mathrm{x}} \mathrm{S}_{1-\mathrm{x}}$ based ReRAM devices are established at room temperature. Nevertheless, the temperature effect on the memory retention characteristics will need to be investigated, because the device temperature may increase during the operation. The effects of Mn-doping and the electrode materials on the ratio of the HRS to LRS are consistent with the results observed in Fig. 4 . The $\mathrm{Mn}$-doped $\mathrm{ZnO}_{x} \mathrm{~S}_{1-\mathrm{x}}$ sputtered thin film turns out to be a suitable material for plastic-based high-performance ReRAM devices.

\section{CONCLUSIONS}

In this study, we investigate the effects of Mn-doping in the resistive switching material of $\mathrm{ZnO}_{\mathrm{x}} \mathrm{S}_{1-\mathrm{x}}$ and electrode material on the memory characteristics of plastic-based ReRAM devices. The Mn-doping increases the ratio of the HRS to LRS, and narrows the distributions of the set and reset voltages, regardless of the electrode materials. For the $\mathrm{ZnO}_{\mathrm{x}} \mathrm{S}_{1-\mathrm{x}}$ thin film, $\mathrm{Cu}$ is appropriate as an electrode material, due to the relatively higher affinity of copper to sulfur. The ratio of the HRS to LRS in the $\mathrm{Al} / \mathrm{ZnO}_{x} \mathrm{~S}_{1}$. : $\mathrm{Mn} / \mathrm{Cu}$ film is above $10^{6}$. The metal-doping in the resistive materials, and the selection of appropriate electrode materials enable plastic-based ReRAM devices with higher performance to be achieved.

\section{ACKNOWLEDGMENTS}

This work was supported by the Basic Science Research Program (NRF-2012R1A1A2042104), and the Mid-Career Researcher Program (NRF-2012R1A2A2A01045613), through the National Research Foundation of Korea (NRF), funded by the Ministry of 
Education, Science, and Technology, and the SK Hynix-Korea University Nano-Semiconductor Program.

\section{REFERENCES}

[1] C. H. Cheng, F. S. Yeh and A. Chin, Adv. Mater. 23, 902 (2011) [DOI: http://dx.doi.org/10.1002/adma.201002946].

[2] K. Kinoshita, T. Okutani, H. Tanaka, T. Hinoki, H. Agura, K. Yazawa, K. Ohmi and S. Kishida, Solid-State Electron 58, 48 (2011) [DOI: http://dx.doi.org/10.1016/j.sse.2010.11.026].

[3] S. K. Hong, J. E. Kim, S. O. Kim, S. Y. Choi and B. J. Cho, IEEE Elec. Dev. Lett. 31, 1005 (2010) [DOI: http://dx.doi.org/10.1109/ LED.2010.2053695].

[4] J. Yun, K. Cho, B. Park, B. H. Park and S. Kim, J. Mater. Chem. 19, 2082 (2009) [DOI: http://dx.doi.org/10.1039/B817062B].

[5] S. Y. Wang, C. W. Huang, D. Y. Lee, T. Y. Tseng and T. Chang, J. Appl. Phys. 108, 114110 (2010) [DOI: http://dx.doi. org/10.1063/1.3518514] .

[6] S. H. Lee, W. G. Kim, S. W. Rhee and K. J. Yong, J. Electrochem. Soc. 155, H92 (2008) [DOI: http://dx.doi. $\operatorname{org} / 10.1149 / 1.2814153]$.

[7] P. Gonon, M. Mougenot, C. Vallée, C. Jorel, V. Jousseaume, H. Grampeix and F. E. Kamel, J. Appl. Phys. 107, 074507 (2010) [DOI: http://dx.doi.org/10.1063/1.3357283].

[8] M. Y. Chan, T. Zhang, V. Ho and P. S. Lee, Microelectron Eng. 85, 2420 (2008) [DOI: http://dx.doi.org/10.1016/ j.mee.2008.09.021].

[9] S. Kim, H. Moon, D. Gupta, S. Yoo and Y. K. Choi, IEEE Trans. Elec. Dev. 56, 696 (2009) [DOI: http://dx.doi.org/10.1109/ TED.2009.2012522].

[10] Z. Q. Wang, H. Y. Xu, X. H. Li, X. T. Zhang, Y. X. Liu and Y. Liu, IEEE Elec. Dev. Lett. 32, 1442 (2011) [DOI: http://dx.doi. org/10.1109/LED.2011.2162311] .

[11] Y. Han, K. Cho and S. Kim, J. Nanosci. Nanotechnol. 12, 5732 (2012) [DOI: http://dx.doi.org/10.1166/jnn.2012.6230].

[12] B. K. Meyer, A. Polity, B. Farangis, Y. He, D. Hasselkamp, T. H.
Krämer and C. Wang, Appl. Phys. Lett. 85, 4929 (2010) [DOI: http://dx.doi.org/10.1063/1.1825053].

[13] H. Y. Peng, G. P. Li, J. Y. Ye, Z. P. Wei, Z. Zhang, D. D. Wang, G. Z. Xing and T. Wu, Appl. Phys. Lett. 96, 192113 (2010) [DOI: http:// dx.doi.org/10.1063/1.3428365].

[14] H. Peng and T. Wu, Appl. Phys. Lett. 95, 152106 (2009) [DOI: http://dx.doi.org/10.1063/1.3249630].

[15] J. G. Kim, H. D. Na, J. H. Oh, D. H. Ko and H. C. Sohn, J. Vac. Sci. Technol. B. 28, 1143 (2010) [DOI: http://dx.doi. org/10.1116/1.3501109].

[16] L. F. Liu, J. F. Kang, N. Xu, X. Sun, C. Chen, B. Sun, Y. Wang, X. Y. Liu, X. Zhang and R. Q. Han, Jpn. J. Appl. Phys. 47, 2701 (2008) [DOI: http://dx.doi.org/10.1143/JJAP.47.2701].

[17] K. A. Bogle, M. N. Bachhav, M. S. Deo, N. Valanoor and S. B. Ogale, Appl. Phys. Lett. 95, 203502 (2009) [DOI: http://dx.doi. org/10.1063/1.3263713].

[18] Y. C. Yang, F. Pan, Q. Liu, M. Liu and F. Zeng, Nano Lett. 9, 1636 (2009) [DOI: http://dx.doi.org/10.1021/nl900006g].

[19] X. Chen, G. Wu and D. Bao, Appl. Phys. Lett. 93, 093501 (2008) [DOI: http://dx.doi.org/10.1063/1.2978158].

[20] W. C. Chien, Y. C. Chen, E. K. Lai, Y. D. Yao, P. Lin, S. F. Hong, J. Gong, T. H. Chou, H. M. Lin, M. N. Chang, Y. H. Shih, K. Y. Hsieh and R. Liu IEEE Elec. Dev. Lett. 36, 126 (2010) [DOI: http:// dx.doi.org/10.1109/LED.2009.2037593].

[21] K. M. Kim, B. J. Choi, Y. C. Shin, S. Choi and C. S. Huang, Appl. Phys. Lett. 91, 012907 (2007) [DOI: http://dx.doi. org/10.1063/1.2749846].

[22] J. Y. Son and Y. H. Shin, Appl. Phys. Lett. 92, 222106 (2008) [DOI: http://dx.doi.org/10.1063/1.2931087].

[23] J. Han, A. M. R. Senos and P. Q. Mantas, J. Eur. Ceram. Soc. 22, 1653 (2002) [DOI: http://dx.doi.org/10.1016/S09552219(01)00484-8].

[24] C. Vallée, P. Gonon, C. Jorel and F. E. Kamel, Appl. Phys. Lett. 96, 233504 (2010) [DOI: http://dx.doi.org/10.1063/1.3447795].

[25] C. Y. Lin, M. H. Lin, M. C. Wu, C. H. Lin and T. Y. Tseng, IEEE Elec. Dev. Lett. 29, 1108 (2008) [DOI: http://dx.doi.org/10.1109/ LED.2008.2002879]. 